04

\title{
Особенности механизма диффузии в структуре алюминий-кремний при облучении ее поверхности внеэлектродной плазмой высоковольтного газового разряда
}

\author{
(C) В.А. Колпаков, С.В. Кричевский
}

Самарский национальный исследовательский университет им. акад. С.П. Королева, 443086 Самара, Россия

e-mail: kolpakov683@gmail.com

Поступило в Редакцию 23 мая 2019 г.

В окончательной редакции 23 мая 2019 г.

Принято к публикации 3 июля 2019 г.

\begin{abstract}
Исследованы особенности механизма диффузии в структуре $\mathrm{Al}-\mathrm{Si}$ в процессе обработки ее поверхности внеэлектродной плазмой высоковольтного газового разряда при токе разряда $I=50 \mathrm{~mA}$, ускоряющем напряжении $U=4 \mathrm{kV}$ и длительностях облучения от 90 до $600 \mathrm{~s}$. Предложена модель для расчета концентрационных профилей распределения примеси алюминия в кремниевой пластине в зависимости от параметров облучения. Получены соответствующие аналитические зависимости, хорошо согласующиеся с экспериментом. Показано, что максимальные значения концентрации диффузанта достигаются на глубине проникновения электронов в полупроводник благодаря формированию ими вакансий в слое толщиной $\sim 0.25 \mu \mathrm{m}$, что сопровождается увеличением на 2-3 порядка коэффициента тепловой диффузии.
\end{abstract}

Ключевые слова: низкотемпературная плазма, высоковольтный газовый разряд, диффузия, механизм, структура $\mathrm{Al}-\mathrm{Si}$, модель, концентрационные профили.

DOI: $10.21883 /$ JTF.2020.01.48662.212-19

\section{Введение}

Исследование особенностей диффузии примесных атомов металла в полупроводнике представляет как фундаментальный, так и значительный прикладной интерес в связи с широким применением диффузионных процессов для изготовления полупроводниковых элементов микро- и наноэлектроники, а также элементов дифракционной оптики и нанофотоники различного назначения [1-4]. Низкотемпературная внеэлектродная плазма является эффективным инструментом, позволяющим стимулировать процесс диффузии, а также регулировать его параметры, т.е. управлять качеством формируемых таким способом элементов [3,4]. Такая плазма широко используется для изготовления омических контактов к полупроводниковым элементам, увеличения адгезии тонких металлических пленок, очистки, а также микро- и наноструктурирования поверхности полупроводниковых и диэлектрических материалов [3-5]. В работах [36] подробно обоснованы преимущества данной плазмы перед низкотемпературной плазмой, формируемой современными технологическими процессами. При обработке структуры пленки металла-полупроводник потоком заряженных частиц плазмы происходят следующие основные процессы, влияющие на диффузию: нагрев пленки металла до температуры плавления, плавление данной пленки, стимулирование возникновения в жидком металле „вакансий“ [7] и управление процессом диффузии атомов полупроводника в жидком металле [4,7]. В работе [7] исследован эффект увлече- ния атомов кремния „вакансиями“, возникающими в расплаве алюминия при облучении поверхности структуры $\mathrm{Al}-\mathrm{Si}$ ионно-электронным потоком внеэлектродной плазмы, а также экспериментально доказана возможность управления потоком „вакансий“ в жидком алюминии и дозированной инжекции атомов полупроводника в расплав путем изменения режимов облучения. Данный эффект наблюдается при длительностях облучения, не превышающих $t \leq 90 \mathrm{~s}$, в течение которых в расплаве устанавливается равновесное состояние. Отмеченный эффект подтвержден в работе [8] при облучении поверхности расплава никеля структуры никель-кремний отрицательными частицами внеэлектродной плазмы. В работе [9] этот эффект применен для формирования каталитической маски на основе жидкого алюминия путем изменения режимов облучения структуры алюминий-кремний отрицательно заряженными частицами высоковольтного газового разряда с целью создания микрорельефа оптических элементов. Необходимо отметить, что в перечисленных работах не исследованы особенности механизма диффузии в структуре $\mathrm{Al}-\mathrm{Si}$ при длительностях облучения, значительно превышающих $t>90 \mathrm{~s}$, когда источником примеси является тонкий слой $\mathrm{Al}$, насыщенный атомами кремния. Однако именно в таком случае появляется возможность формирования глубоких областей легирования кремния акцепторной примесью и управления структурой $p-n$ перехода. Кроме того, тяжело найти работы, в которых даются не качественные, а количественные концентрационные профили распределения атомов алюминия в 
кремнии в зависимости от конкретных технологических параметров обработки структуры $\mathrm{Al}-\mathrm{Si}$. Таким образом, целью настоящей работы является создание модели для расчета концентрационных профилей распределения примеси алюминия в кремниевой пластине в зависимости от параметров облучения структуры $\mathrm{Al}-\mathrm{Si}$ ионноэлектронным потоком внеэлектродной плазмы, формируемой высоковольтным газовым разрядом, что позволит расширить имеющиеся теоретические знания о процессах диффузии в структурах металл-полупроводник при их облучении потоками низкотемпературной плазмы.

\section{Методика проведения эксперимента}

В качестве исходного полупроводника использовали пластины кремния марки КЭФ-32 кристаллографической ориентации (111), диаметром $D_{2}=50 \mathrm{~mm}$ и толщиной $H=1 \mathrm{~mm}$, на поверхность которых термовакуумным методом на установке УВН-2М-1 $[3,4,10]$ наносили слой алюминия толщиной $h=0.1 \mu \mathrm{m}$. Поверхность алюминия полученной структуры облучали направленным потоком отрицательных частиц внеэлектродной плазмы с энергией частиц $0.3-6 \mathrm{keV}$ и током разряда 0-140 mA. Длительность обработки не превышала $600 \mathrm{~s}$. Для увеличения эмиссии электронов катод изготавливали из алюминия, а для увеличения равномерности распределения частиц плазмы по энергиям активную область анода изготавливали в виде сетки, выполненной из нержавеющей стали, что значительно снижало ее химическую активность с частицами плазмы, но увеличивало стойкость к температурному нагреву [4]. Рабочим газом служил воздух, откачиваемый до исходных давлений $10^{-4}-10^{-2}$ Torr. Напуском рабочего газа устанавливали давление $10^{-1}-10^{-2}$ Torr, после чего на электроды газоразрядного устройства подавали высокое напряжение $U=4 \mathrm{kV}$. Неравномерность распределения энергии частиц по сечению потока газоразрядной плазмы была не хуже 98\% [3]. Температура поверхности образца в области облучения определялась микропирометром типа „Проминь“, a также с помощью способа оценки, позволяющего определять искомый граничный режим относительно величины теплового воздействия и теплофизических параметров материала [11]. Содержание $\mathrm{Al}$ в $\mathrm{Si}$ определялось с помощью измерения поверхностного сопротивления диффузионного слоя 4-х зондовым методом при последовательном снятии тонких слоев вещества.

\section{Результаты и их обсуждение}

Рассмотрим схему облучения структуры $\mathrm{Al}-\mathrm{Si}$ ионноэлектронным потоком внеэлектродной плазмы, формируемой высоковольтным газовым разрядом, представ-

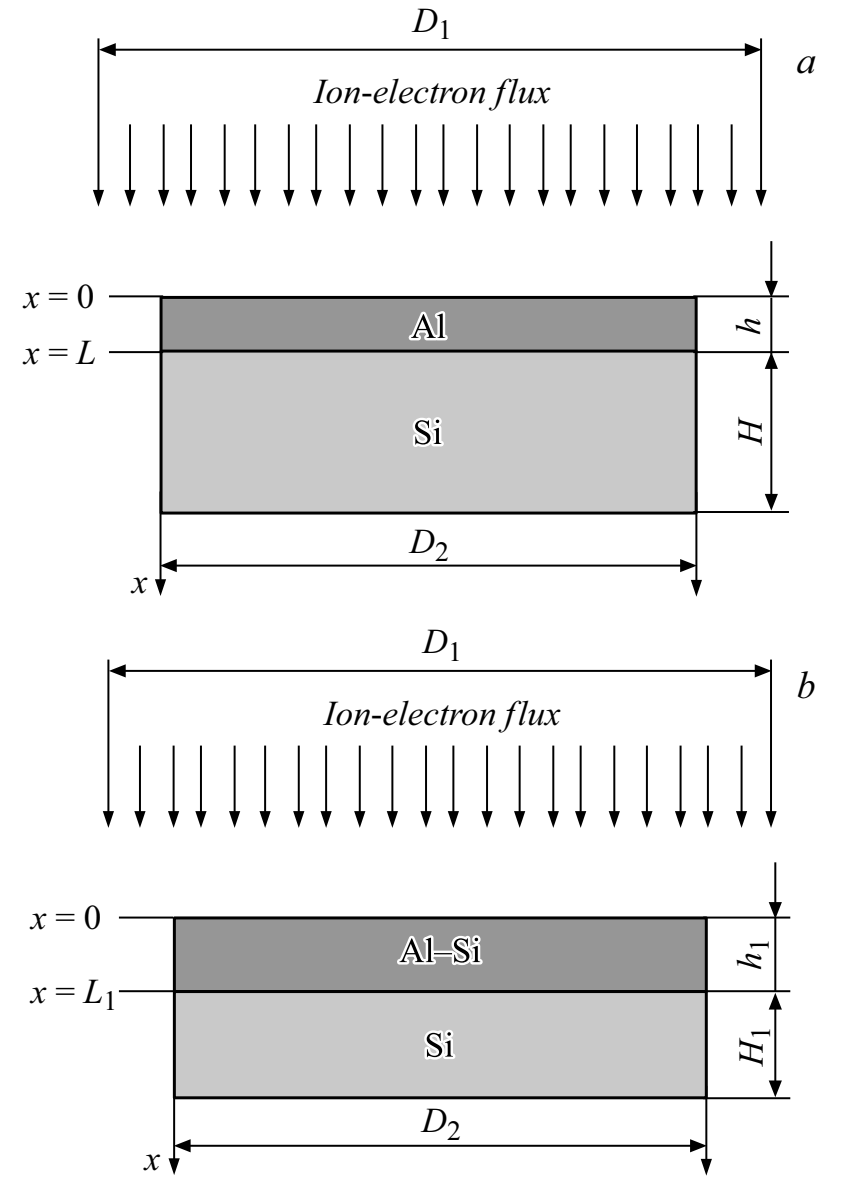

Рис. 1. Схема облучения структуры $\mathrm{Al}-\mathrm{Si}$ ионноэлектронным потоком внеэлектродной плазмы, формируемой высоковольтным газовым разрядом: $a-$ при длительностях облучения, не превышающих $t \leq 90 \mathrm{~s} ; b-$ при длительностях облучения, превышающих $t>90 \mathrm{~s}$.

ленную на рис. 1, которая будет использована для построения упомянутой ранее модели.

При облучении ионно-электронным потоком внеэлектродной плазмы во взаимодействие с поверхностью алюминия вступают отрицательно заряженные частицы - электроны и отрицательные ионы - с энергиями, достаточными для нагрева структуры $\mathrm{Al}-\mathrm{Si}$, перехода алюминия из твердого состояния в жидкое, а также образования градиента „вакансий“ в приповерхностном слое жидкого Al, концентрация которых соответствует концентрации частиц в ионно-плазменном потоке, что приводит к формированию потока „вакансий“ в направлении поверхности полупроводника [7]. Вакансионный механизм диффузии лежит в основе отмеченного ранее эффекта увлечения атомов кремния „вакансиями“, а также соответствующей модели процесса растворения атомов полупроводника в расплаве алюминия при облучении структуры $\mathrm{Al}-\mathrm{Si}$ ионно-электронным потоком. Указанный механизм, эффект и модель, справедливые для длительностей облучения, не превышающих $t \leq 90 \mathrm{~s}$, 
Таблица 1. Значения температуры рабочей поверхности образца при токе разряда $I=50 \mathrm{~mA}$ и $U=4 \mathrm{kV}$, а также различных значениях длительности обработки в плазме

$t, \mathrm{~S}$

\begin{tabular}{c|c|c|c|c|c|c|}
\hline \multirow{2}{*}{$I, \mathrm{~mA}$} & \multicolumn{7}{|c}{ Значения температуры рабочей поверхности образца $T_{0}, \mathrm{~K}$} \\
\cline { 2 - 7 } & 100 & 200 & 300 & 400 & 500 & 600 \\
\hline 50 & 1198 & 1203 & 1208 & 1213 & 1218 & 1223
\end{tabular}

Таблица 2. Значения разности температур рабочей поверхности и нижнего основания образца при токе разряда $I=50 \mathrm{~mA}$ и $U=4 \mathrm{kV}$, а также различных значениях длительности обработки в плазме

$t, \mathrm{~s}$

\begin{tabular}{c|c|c|c|c|c|c}
\hline \multirow{2}{*}{$I, \mathrm{~mA}$} & \multicolumn{6}{|c}{ Значения разности температур рабочей поверхности и нижнего основания образца $\Delta T, \mathrm{~K}$} \\
\cline { 2 - 7 } & 100 & 200 & 300 & 400 & 500 & 600 \\
\hline 50 & 583 & 572 & 564 & 553 & 544 & 536 \\
\hline
\end{tabular}

в течение которых происходит насыщение расплава атомами $\mathrm{Si}$ и устанавливается равновесное состояние, подробно рассматривались в работах $[3,4,7]$. Однако в этих работах осталась неучтенной зависимость коэффициента диффузии от температуры, что особенно критично для полупроводниковых материалов в больших диапазонах рабочих температур и длительностей облучения. Между тем при высокой концентрации в расплаве комплексов $\mathrm{Al}-\mathrm{Si}$ или даже при их слиянии процесс генерации „вакансий“ прекращается [7]. В то же время продолжается действие ионно-электронного потока, которое позволяет создать в рассматриваемой структуре значительный градиент температуры, под влиянием которого, а также теплового движением атомов, в дальнейшем при длительностях облучения $t>90 \mathrm{~s}$ осуществляется диффузия атомов алюминия в материал полупроводника. Кроме того, бомбардировка отмеченной структуры отрицательными ионами и электронами должна способствовать образованию дефектов (вакансий) в приповерхностном слое кремния, которые вносят свой вклад в протекание диффузии примесных атомов в полупроводнике. Протекание такой диффузии подтверждается тем, что после окончания процесса, при удалении насыщенного атомами Si-cлоя с полупроводниковыми свойствами, возникает визуально наблюдаемый блестящий слой металлического $\mathrm{Al}$, удаление которого необходимо осуществлять уже в горячей соляной кислоте $[3,4]$. Рассмотрим этот процесс подробнее.

Обработка ионно-электронным потоком внеэлектродной плазмы поверхности структуры, представленной на рис. 1, приводит к нагреву образца. В работе [11] подробно осуществлено решение тепловой задачи, касающейся определения температуры поверхности отмеченного образца в области ее взаимодействия с потоком внеэлектродной плазмы, с помощью которой получены результаты для тока разряда $I=50 \mathrm{~mA}$ и $U=4 \mathrm{kV}$, представленные в табл. 1 и 2. Анализ данных результатов позволяет считать распределение температуры в образце линейным, а величину градиента температуры - отрицательной $(G<0)$, т. е. перепад температур в образце $\Delta T<T_{0}$. С учетом этого, коэффициент диффузии алюминия в кремний можно записать в виде [12]

$$
D_{T}=D_{0} \exp \left[-\frac{E}{k\left(T_{0}+G x\right)}\right],
$$

где $D_{0} \approx 8 \mathrm{~cm}^{2} / \mathrm{s}$ - коэффициент, почти не зависящий от температуры [13], $E=3.39 \mathrm{eV}$ [12] - энергия активации диффузии алюминия в кремний. Однако, как было отмечено ранее, на протекание диффузии в полупроводнике оказывает влияние и бомбардировка образца отрицательными ионами и электронами путем образования вакансий в приповерхностном слое кремния. Оценим возможность протекания такого процесса. Поскольку рабочим газом является воздух, с поверхностью образца вступают во взаимодействие два сорта частиц: электроны и отрицательные ионы кислорода. Последние, ввиду большей массы и меньшей по сравнению с электронами скоростью, вступают во взаимодействие непосредственно на поверхности рассматриваемой структуры, тратя свою энергию на нагрев образца и, создавая значительные градиенты температуры, образуют поверхностный тепловой источник. Электроны же способны проникнуть в объем полупроводника на определенную глубину, равную [14]:

$$
L^{*}=10^{-5} \frac{U^{3 / 2}}{\rho},
$$

где $\rho=2.33 \mathrm{~g} / \mathrm{cm}^{3}$ - плотность кремния; $U=4 \mathrm{kV}$ ускоряющее напряжение; $\quad L^{*}=0.35 \mu \mathrm{m}, \quad$ что 
Таблица 3. Значения коэффициента диффузии алюминия в кремнии, соответствующие разным значениям $x$ и длительности обработки при $I=50 \mathrm{~mA}$ и $U=4 \mathrm{kV}$

$$
t, \mathrm{~s}
$$

\begin{tabular}{l|c|c|c}
\hline \multirow{2}{*}{$x, \mu \mathrm{m}$} & \multicolumn{3}{|c}{$\begin{array}{c}\text { Значения коэффициента диффузии алюминия в кремнии, соответствующие разным значениям } x \\
\text { и длительности обработки при } I=50 \mathrm{~mA} \text { и } U=4 \mathrm{kV} D_{T} \text { и } D_{T}\left(C_{\mathrm{Si}}^{V}\right), \mathrm{cm}^{2} / \mathrm{s}\end{array}$} \\
\cline { 2 - 4 } & 100 & 300 & 600 \\
\hline 0 & $0.568 \cdot 10^{-13}$ & $0.590 \cdot 10^{-13}$ & $0.882 \cdot 10^{-13}$ \\
0.1 & $0.450 \cdot 10^{-13}$ & $0.589 \cdot 10^{-13}$ & $0.881 \cdot 10^{-13}$ \\
0.25 & $0.577 \cdot 10^{-11}$ & $2.270 \cdot 10^{-11}$ & $4.740 \cdot 10^{-11}$ \\
0.4 & $0.562 \cdot 10^{-13}$ & $0.588 \cdot 10^{-13}$ & $0.877 \cdot 10^{-13}$
\end{tabular}

на $\quad 0.2-0.3 \mu \mathrm{m}$ превышает толщину насыщенного атомами $\mathrm{Si}$ слоя с полупроводниковыми свойствами $h_{1}$ (см. рис. 1,b). Распределение энергетических потерь электрона по глубине пробега в этом случае можно описать законом Томсона-Виддингтона [15]. В конце своего пути электрон выделяет почти всю свою энергию $(\varepsilon)$, которая расходуется на разрыв связей между атомами полупроводника и образование вакансий в $\mathrm{Si}$ на глубине $L^{*}$. Энергия, передаваемая электроном атому кремния при взаимодействии с ним, определяется из выражения [7]:

$$
\Delta T_{e}=\frac{2 e U m_{e}}{M_{\mathrm{Si}}}
$$

где $M_{\mathrm{Si}}$ - масса атома кремния; $m_{e}$ - масса электрона. Подставляя в (3) $M_{\mathrm{Si}}=46.5 \cdot 10^{-27} \mathrm{~kg}$ и $U=4 \mathrm{kV}$, а также массу электрона $m_{e}=9.1 \cdot 10^{-31} \mathrm{~kg}$, получим $\Delta T_{e}=0.23 \mathrm{eV}$. Поскольку энергия образования вакансий в кремнии лежит в диапазоне $2.1-2.3 \mathrm{eV}$ [16], один электрон за 10 столкновений или 10 электронов одновременно способны образовать вакансию в $\mathrm{Si}$ на глубине $L^{*}$. Следовательно, при энергии электрона $4 \mathrm{keV}$, которую он практически полностью выделяет в конце своего пути в полупроводнике, тратя в каждом соударении с атомами кремния $0.23 \mathrm{eV}$, электрон способен образовать порядка $1.9 \cdot 10^{3}$ вакансий. При этом концентрация таких вакансий соответствует концентрации электронов в ионно-плазменном потоке. Количество электронов, поглощенных слоем кремния единичной площади в единицу времени на глубине $L^{*}$, которые принимают участие в образовании вакансий, можно оценить по формуле [8]:

$$
N_{e}=\frac{1}{e S}\left(5.75 \cdot 10^{-6} \frac{U^{1.35}}{\rho}-\rho \operatorname{erf} \frac{1.15 \cdot 10^{-5}}{\sqrt{\pi}} U^{1.35}\right) .
$$

Тогда выражение для определения концентрации вакансий, образованных электронами в полупроводнике на глубине $L^{*}$ за время $t$ запишется в виде

$$
C_{\mathrm{Si}}^{V}=\frac{N_{e}}{L^{*}} \frac{\varepsilon}{\Delta E_{V}} t
$$

где $\Delta E_{V}$ - энергия образования вакансий в кремнии, равная $\Delta E_{V}=2.1 \mathrm{eV}$. Оценка величины $C_{\mathrm{Si}}^{V}$, например для $t=600 \mathrm{~s}$, дает значение $C_{\mathrm{Si}}^{V}=0.81 \cdot 10^{22} \mathrm{~cm}^{-3}$. Таким образом, под действием электронной бомбардировки структуры $\mathrm{Al}-\mathrm{Si}$ в режимах, характерных для настоящей работы, возможно образование вакансий в кремнии, которые, безусловно, оказывают влияние на диффузию наряду с градиентом температуры, создаваемым поверхностным тепловым источником, что хорошо согласуется с результатами работ $[12,16]$. Тогда коэффициент диффузии $D_{T}$ (см. формулу (1)) будет иметь функциональную зависимость от концентрации вакансий, и его можно записать в следующем виде аналогично случаю, рассмотренному в работах $[3,4]$ :

$$
D_{T}\left(C_{\mathrm{Si}}^{V}\right)=\left(\frac{C_{\mathrm{Si}}^{V}}{C_{0}}\right) D_{T}
$$

где $C_{0}$ - максимальная концентрация атомов алюминия в кремнии, которая при температурах $1198-1223 \mathrm{~K}$ составляет порядка $C_{0} \approx 1.5 \cdot 10^{19} \mathrm{~cm}^{-3}$ [16]. С помощью полученного выражения в настоящей работе предлагается проводить оценку коэффициента диффузии на глубине проникновения электронов в полупроводник, равной $L-h_{1}$, т.е. $x \approx 0.25 \mu \mathrm{m}$. С учетом этого значения величин $D_{T}$ и $D_{T}\left(C_{\mathrm{Si}}^{V}\right)$, рассчитанных с помощью формул (1) и (6) (для $x \approx 0.25 \mu \mathrm{m}$ ) при разных $x$ и $t$, представлены в табл. 3. Анализ данных результатов показывает изменение $D_{T}$ в диапазоне от $0.450 \cdot 10^{-13}$ до $0.882 \cdot 10^{-13} \mathrm{~cm}^{2} / \mathrm{s}$, в то время как величина $D_{T}\left(C_{\mathrm{Si}}^{V}\right)$ изменяется в пределах от $0.577 \cdot 10^{-11}$ до $4.740 \cdot 10^{-11} \mathrm{~cm}^{2} / \mathrm{s}$, что на 2-3 порядка выше коэффициента тепловой диффузии.

Таким образом, зная закономерность изменения данных в табл. 1-3, а также принимая во внимание сделанные выше рассуждения, свидетельствующие о неизотермическом характере диффузии в рассматриваемом случае и влиянии на нее вакансий, образованных электронами в кремнии на глубине $x \approx 0.25 \mu \mathrm{m}$, можно определить концентрацию диффузанта в образце с помо- 
щью следующего выражения:

$$
C(x, t)=\left\{\begin{array}{l}
\sqrt{\frac{2 t}{\pi k_{1}}} C_{0} \frac{\xi^{\left(3-k_{2}\right) / 2}}{\sqrt{\xi}-1} e^{-k_{1}(\sqrt{\xi}-1)^{2} / 4 t} \\
\text { при } 0 \leq x<L-h_{1} \text { и } L-h_{1}<x \leq h_{1}+H_{1}, \\
\frac{D_{T}\left(C_{\mathrm{Si}}^{V}\right)}{D_{T}\left(T_{0}\right)} \sqrt{\frac{2 t}{\pi k_{1}}} C_{0} \frac{\xi^{\left(3-k_{2}\right) / 2}}{\sqrt{\xi}-1} e^{-k_{1}(\sqrt{\xi}-1)^{2} / 4 t} \\
\text { при } x=L-h_{1},
\end{array}\right.
$$

где

$$
D_{T}\left(T_{0}\right)=D_{0} \exp \left(-\frac{E}{k T_{0}}\right)
$$

- коэффициент диффузии, соответствующий температуре рабочей поверхности образца на границе $x=0$ (табл. 3). Первое выражение в (7) определяет концентрационный профиль диффундирующих атомов при неизотермической диффузии [12], в котором обозначено

$$
k_{1}=\frac{1}{D_{T}\left(T_{0}\right) \alpha^{2}}, \alpha=\frac{E G}{k T_{0}^{2}}, k_{2}=\left(2-\frac{Q^{*}}{E}\right), \xi=e^{-\alpha x},
$$

где $Q^{*}$ - теплота переноса. Это выражение справедливо, когда показатель экспоненты

$$
\frac{k_{1}(\sqrt{\xi}-1)^{2}}{4 t}>1 \text {. }
$$

В настоящей работе указанное условие выполняется, поэтому применение отмеченных выражений оправдано. Второе выражение в (7) определяет концентрацию примесных атомов алюминия на глубине проникновения электронов в кремний с учетом влияния на диффузию образованных электронами вакансий. Осуществляя расчет по формулам (1)-(7) и используя данные, содержащиеся в табл. 1-3, получим концентрационные профили распределения атомов алюминия в кремниевой пластине в зависимости от параметров облучения структуры $\mathrm{Al}-\mathrm{Si}$ ионноэлектронным потоком внеэлектродной плазмы, формируемой высоковольтным газовым разрядом, представленные на рис. 2.

Анализ кривых, представленных на рис. 2, свидетельствует о том, что их характер изменения объясняется протеканием диффузий под действием градиентов концентрации, температуры и вакансий, формируемых электронами на глубине их проникновения в полупроводник. Разные значения величины $C$ на границе $x=0$, соответствующие кривым $1-3$, объясняются протеканием термодиффузии, при которой перенос диффузанта, его дрейф осуществляется в поле градиента температуры [12]. С увеличением длительности облучения количество атомов алюминия, перешедших в объем кремния под действием термодиффузии, возрастает, одновременно уменьшая их концентрацию на границе $x=0$. Количество растворенных атомов диффузанта, которые обладают энергией, необходимой

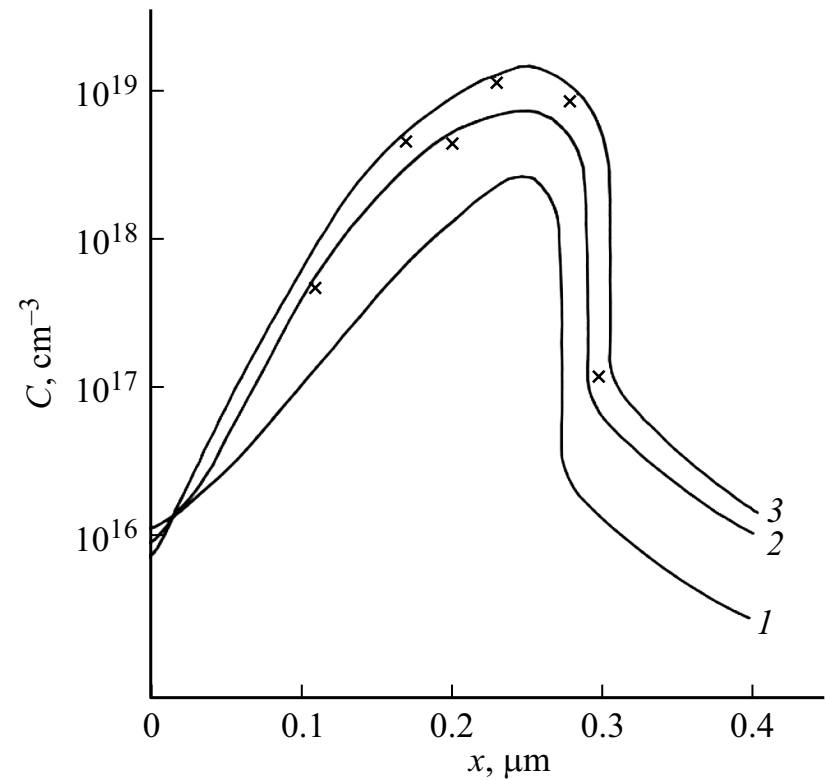

Рис. 2. Распределение концентрации атомов алюминия в кремниевой пластине после обработки структуры $\mathrm{Al}-\mathrm{Si}$ ионноэлектронным потоком внеэлектродной плазмы, формируемой высоковольтным газовым разрядом при токе разряда $I=50 \mathrm{~mA}, U=4 \mathrm{kV}$ и разных длительностях облучения $t: 1-$ 100; 2 - 300; 3 - 600 s. (Непрерывные линии получены с помощью расчета по формулам (7); измерения проводились четырехзондовым методом).

для перехода в соседнее положение, изменяется вдоль направления градиента температуры. В то же время существует самостоятельный поток диффузанта, формируемый градиентом его концентрации, направленный вглубь образца. Максимальные значения концентрации диффузанта достигаются на глубине проникновения электронов в полупроводник благодаря формированию ими вакансий в слое $(x \approx 0.25 \mu \mathrm{m})$, что сопровождается увеличением на 2-3 порядка коэффициента тепловой диффузии (табл. 3). Значениям $t_{1}=100 \mathrm{~s}$, $t_{2}=300 \mathrm{~s}, t_{3}=600 \mathrm{~s}$ соответствуют свои значения величины $D_{T}\left(C_{\mathrm{Si}}^{V}\right)$, равные $0.577 \cdot 10^{-11}, 2.270 \cdot 10^{-11}$ и $4.740 \cdot 10^{-11} \mathrm{~cm}^{2} / \mathrm{s}$, что приводит к разным положениям максимума на кривых 1-3. При этом для всех кривых максимумы не превышают предела растворимости атомов диффузанта в образце, равного $C_{0} \approx 1.5 \cdot 10^{19} \mathrm{~cm}^{-3}$. Дальнейший характер изменения кривых при $0.25 \leq x \leq 0.4 \mu$ m соответствует концентрационному распределению при неизотермической диффузии для случая $Q^{*}>0$, представленного в работе [12].

Для подтверждения стимуляции диффузии атомов алюминия в кремний при длительных временах облучения проводился эксперимент, целью которого являлось сравнение глубин легирования алюминия в кремний при действии на структуру $\mathrm{Al}-\mathrm{Si}$ чисто теплового поля и ионно-электронного облучения. Для это- 


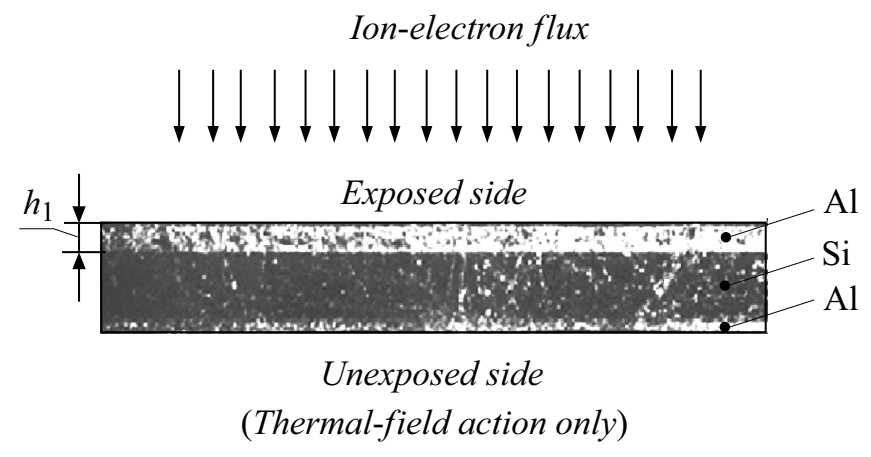

Рис. 3. Косой шлиф микроструктуры алюминий-кремний-алюминий.

го на обеих поверхностях кремниевой пластины формировался слой алюминия порядка нескольких микрон. Верхняя сторона структуры $\mathrm{Al}-\mathrm{Si}-\mathrm{Al}$ подвергалась облучению ионно-электронным потоком с током $I=50 \mathrm{~mA}$ и ускоряющим напряжением $U=4 \mathrm{kV}$ в течение $t=600 \mathrm{~s}$, в то время как нижняя - действию только теплового поля. Измерение глубин легирования осуществлялось металлографическим способом путем применения метода косого шлифа $\left(\alpha=7^{\circ}\right)$ [10]. Окрашивание легированных слоев происходило в раствоpe, состоящем из смеси $0.05-0.1 \%$ азотной (70\%ой) и $(48 \%$-ой $)$ плавиковой кислот. Для получения изображения косового шлифа использовался оптический микроскоп МИИ-4. Вид косого шлифа представлен на рис. 3.

Зона легирования со стороны облучения (верхняя часть на рис. 3 высотой $h_{1}$ ) практически в три раза превышает зону легирования поверхности кремния, не подвергавшейся действию облучения, хотя обе стороны находились практически при одной и той же температуре, равной $1123 \mathrm{~K}$. Таким образом, стимуляция диффузии при ионно-электронном облучении действительно существует. В этом случае, как показал анализ зависимостей, представленных на рис. 2, варьированием режимов облучения достигается дозированное изменение концентрации атомов алюминия в кремнии, а следовательно, и глубины легирования $\left(h_{1}\right)$ полупроводника маскирующим материалом.

\section{Заключение}

С использованием разработанной модели проведен расчет концентрационных профилей распределения атомов алюминия в кремнии в зависимости от конкретных технологических параметров обработки структуры $\mathrm{Al}-\mathrm{Si}$ ионно-электронным потоком внеэлектродной плазмы, формируемой высоковольтным газовым разрядом. Установлено, что характер изменения зависимостей объясняется протеканием диффузий под действием градиентов концентрации, температуры и вакансий, формируемых электронами на глубине их проникновения в полупроводник. В рамках модели осуществлен расчет значений коэффициента диффузии алюминия в кремний, соответствующих разным значениям $x$ и длительности обработки при токе разряда $I=50 \mathrm{~mA}$ и ускоряющем напряжении $U=4 \mathrm{kV}$. Показано, что на глубине проникновения электронов в полупроводник коэффициент диффузии имеет функциональную зависимость от концентрации вакансий, а величина $D_{T}\left(C_{\mathrm{Si}}^{V}\right)$ на 2-3 порядка выше коэффициента тепловой диффузии $D_{T}$, из-за чего в данной области достигаются максимальные значения концентрации диффузанта. Экспериментально подтверждены адекватность разработанной модели и возможность дозированного изменения концентрации атомов алюминия в кремнии, а следовательно, и глубины легирования $\left(h_{1}\right)$ полупроводника маскирующим материалом, посредством варьирования режимов облучения структуры $\mathrm{Al}-\mathrm{Si}$.

\section{Конфликт интересов}

Авторы заявляют, что у них нет конфликта интересов.

\section{Список литературы}

[1] Franssila S. Introduction to Microfabrication. John Wiley \& Sons, 2010. 517 p.

[2] Diffractive Nanophotonics / Ed. by V.A. Soifer. Taylor and Francis, 2014. 704 p.

[3] Kazanskiy N.L., Kolpakov V.A. Optical Materials: Microstructuring Surfaces with Off-Electrode Plasma. CRC Press, 2017. 211 p.

[4] Казанский Н.Л., Колпаков В.А. Формирование оптического микрорельефа во внеэлектродной плазме высоковольтного газового разряда. М.: Радио и связь, 2009. 220 с.

[5] Kazanskiy N.L., Kolpakov V.A., Podlipnov V.V. // Vacuum. 2014. N 101. P. 291-297.

[6] Колпаков В.А., Кричевский С.В., Маркушин М.A. // ЖЭТФ. 2017. Т. 151. Вып. 1. С. 189-198. [Kolpakov V.A., Krichevsky S.V., Markushin M.A. // J. Experiment. Theor. Phys. 2017. Vol. 124. N 1. P. 164-171.]

[7] Колпаков В.А., Колпаков А.И. // Письма в ЖТФ. 1999. T. 25. Вып. 15. С. 58-65.

[8] Колпаков В.А., Подлипнов В.В. // ЖТФ. 2015. Т. 85. Вып. 1. C. 52-55. [ Kolpakov V.A., Podlipnov V.V. // Tech. Phys. 2015. Vol. 60. N 1. P. 53-56.]

[9] Казанский Н.Л., Колпаков А.И., Колпаков В.А. // Компьютерная оптика. 2002. № 24. С. 84-90.

[10] Курносов А.И., Юдин В.В. Технология производства полупроводниковых приборов. М.: Высшая школа, 1974. 400 с.

[11] Колпаков В.А., Новомейский Д.Н., Новоженин М.П. // ЖТФ. 2013. Т. 83. Вып. 11. С. 6-9. [Kolpakov V.A., Novomeiskii D.N., Novozhenin M.P. // Tech. Phys. 2013. Vol. 58. N 11. P. 1554-1557.]

[12] Майрановский Г.В., Фистуль В.И., Фистуль М.В. // ФТП. 1985. Т. 19. Вып. 11. С. 2082-2085. 
[13] Бушуев В.А., Петраков А.П. // ЖТФ. 2000. Т. 70. Вып. 5. C. 92-96. [Bushuev V.A., Petrakov A.P. // Tech. Phys. 2000. Vol. 45. N 5. P. 613-617.]

[14] Рыкалин Н.Н., Зуев И.В., Углов И.В. Основы электроннолучевой обработки материалов. М.: Машиностроение, 1978. 222 c.

[15] Попов В.К. // ФХОМ. 1967. N 4. C. 11-24.

[16] Atomic Diffusion in Semiconductors / Ed. by D. Shaw. Plenum Press, 1973. $685 \mathrm{p}$. 